\title{
Application of Experimental Design to Optimize the Morphological Nature of Synthesized Transition Metal Oxide Nanoparticles by Co - Precipitation method using PVP as Optimizer
}

\author{
M. Basurudeen ${ }^{\mathrm{a}^{*}}$ and E. Christy Jerin ${ }^{\mathrm{a}}$ \\ ${ }^{a}$ Deartment of physics, St. John's College, Palayamkottai, Tirunelveli, Tamilnadu, India.
}

\begin{abstract}
Metal Oxide ( $\mathrm{CuO}, \mathrm{ZnO}$ and $\mathrm{CdO})$ Nanoparaticles were synthesized by Co-Precipitation Method Using PVP as Optimizer and same concentration of the precursors. The Formation of $(\mathrm{CuO}, \mathrm{ZnO}$ and $\mathrm{CdO})$ Nanoparticles were confirmed by XRD, UV - Visible, FT-IR and FESEM Studies. The Average particle size have been found to be about $44 \mathrm{~nm}, 39 \mathrm{~nm}, 45 \mathrm{~nm}$.The FESEM CuO image reveal the product consist of spherical particles in the range of $20 \mathrm{~nm}-30 \mathrm{~nm}$ and $\mathrm{ZnO}$ image reveal the product consist of nanoflakes in the range of $15 \mathrm{~nm}-30 \mathrm{~nm}$. The UV-Analysis, Results shows that the Bandgap value of $\mathrm{CuO}, \mathrm{ZnO}$ and $\mathrm{CdO}$ nanoparticles are $2.3 \mathrm{eV}, 2 \mathrm{eV}$ and $3.9 \mathrm{eV}$.
\end{abstract}

Keywords: Polyvinylpyrrolidone, Co- precipitation, XRD, FTIR, UV, FE-SEM, CuO, ZnO and CdO.

\section{Introduction}

One of the important goals of materials research is to develop ways of obtaining materials to exploit the peculiar properties and unique applications. In recent years, nanoparticles have attracted great interest because of their unique chemical and physical properties, which are different from those of either the bulk materials or single atoms. Among these nanoparticles, it is, especially, metal oxide nanoparticles that exhibit the technological importance for solar cell, chemical sensor and liquid crystal display.Particles with sizes between 1 and $100 \mathrm{~nm}$ are called nanoparticles, which have one or more dimensions. One of the unique properties of nanoparticles is their large surface area to volume ratio, which gives them different properties compared with bulk materials that are made from the same substances. The oxides of transition metals are an important class of semiconductors, which have applications in magnetic storage media, solar energy transformation, electronics and catalysis .

Copper oxide $(\mathrm{CuO})$ is a p type semiconductor with a narrow band gap of about $1.2 \mathrm{eV}$ to $1.5 \mathrm{eV}$ has been widely exploited for a versatile range of applications such as catalysis. In recent years, nanostructures of transition metal oxides have gained a great attention from material scientists and engineers due to their different properties compared with the corresponding bulk counterparts, which in turns provides promising applications in various fields of technology. Preparation of high quality nanostructures of defined, controllable size and morphology is a critical requirement in order to develop nano-devices or other different applications for catalyst, sensing. $\mathrm{CuO}$, categorized into transition metal oxide group, is a $\mathrm{p}$ type, narrow bandgap semiconductor. It has monoclinic structure and many interesting characteristics: super thermal conductivity, photovoltaic properties, high stability and antimicrobial activity. Due to such exclusive properties, $\mathrm{CuO}$ can be used in many technological fields for example: active catalyst, gas sensor.

Zinc oxide is an inorganic compound with the formula $\mathrm{ZnO}$. It usually appears as a white powder, nearly insoluble in water. The powder is widely used as an additive into numerous materials and products including plastics, ceramics, glass, cement, rubber (e.g. car tyres), lubricants, paints, ointments, adhesives, sealants, pigments, foods (source of $\mathrm{Zn}$ nutrient), batteries, ferrites, fire retardants, etc. $\mathrm{ZnO}$ is present in the Earth crust as a mineral zincite; however, most $\mathrm{ZnO}$ used commercially is produced synthetically. In materials science, $\mathrm{ZnO}$ is often called a II-VI semiconductor because zinc and oxygen belong to the 2nd and 6th groups of the periodic table, respectively. This semiconductor has several favourable properties: good transparency, high electron mobility, wide bandgap, strong roomtemperature luminescence, etc. Those properties are already used in emerging applications for transparent electrodes in liquid crystal displays and in energy-saving or heatprotecting windows, and electronic applications of $\mathrm{ZnO}$ as thin-film transistor.

Cadmium oxide is an important n-type semiconductor with a direct band gap of $2.3 \mathrm{eV}$ and an indirect band gap of $1.36 \mathrm{eV}$, and has promising applications in the wide fields such as solar cells, photo transistors, transparent electrodes, catalysts and gas sensors. Up to now, many methods have been employed to obtain the useful material, such as sol-gel, solvothermal, microemulsion, precipitation and sonochemical methods. It 
seemed that, in the process of the synthesis, complex conditions and long synthesis time might be required for these technologies.

Polyvinylpyrrolidone (PVP) is the most commonly used polymer in the preparation of metal oxides because of its distinct shape, dissolved metal salts, and transport facility.In the present work, we have $\mathrm{CuO}, \mathrm{ZnO}$ and $\mathrm{CdO}$ Nanoparticles were synthesized by Co- precipitation method using PVP and the main aim of our work is to optimize the morphological nature of the synthesized Nanoparticles using PVP as optimizer; PVP was chosen to function as a stabilizer and $\mathrm{NaOH}$ as a precursure. Efforts were focused on the changes in size and appeared different morphological structure.

\subsection{Materials:}

\section{Experimental}

Application of experimental design to optimize the morphological nature of synthesized nanoparticles by coprecipitation method using PVP as optimizer. The following materials were used. Copper Chloride $\left(\mathrm{CuCl}_{2}\right)$, Zinc Chloride $\left(\mathrm{ZnCl}_{2}\right)$, Cadmium Chloride $\left(\mathrm{CdCl}_{2}\right)$, Sodium Hydroxide $(\mathrm{NaOH})$, Polyvinyl Pyrolidine (PVP) and Distilled Water

\subsection{Experimental:}

Metal Oxide $(\mathrm{CuO}, \mathrm{ZnO}$ and $\mathrm{CdO})$ Nanoparaticles were synthesized by Co-Precipitation Method Using PVP as Optimizer. First, $0.5 \mathrm{M}$ of was $\mathrm{CuCl}_{2}$ dissolved in $100 \mathrm{ml}$ of distilled water. This solution was stirred using magnetic stirrer at $660 \mathrm{rpm}$ for $30 \mathrm{~min}$. It gives a green color transparent solution (solution A). Second, $0.25 \mathrm{M}$ of $\mathrm{NaOH}$ is made to dissolve in $100 \mathrm{ml}$ of distilled water. This solution was stirred using magnetic stirrer at $580 \mathrm{rpm}$ for 30min. It gives clear solution (solution B). Then $0.1 \mathrm{M}$ of PVP mixed in both solution together using magnetic stirrer at $510 \mathrm{rpm}$ for 1 hour to get pure $\mathrm{CuO}$ solution. Same procedure was repeated again, but by the same molarity of $\mathrm{ZnCl}_{2}$ as $0.5 \mathrm{M}, 0.25 \mathrm{M}$ of $\mathrm{NaOH}$ with PVP as $0.1 \mathrm{M}$. A large amount of white precipitate was produced. Again same procedure was repeated, but by the same molarity of $\mathrm{CdCl}_{2}$ as $0.5 \mathrm{M}, 0.25$ $\mathrm{M}$ of $\mathrm{NaOH}$ with PVP as $0.1 \mathrm{M}$. A large amount of white precipitate was produced. The transparent solutions change into a colloidal solution. Filtered the colloidal solutions. Then the green precipitate and white precipitates were collected. It become a gel states. The collected samples were washed thrice with the distilled water and dried in the oven at $100^{\circ} \mathrm{C}$ for $3 \mathrm{hrs}$. Then dried samples grained finely with mortor. Finally, to get $\mathrm{CuO}, \mathrm{ZnO}$ and $\mathrm{CdO}$ Nanoparticles. The obtained $\mathrm{CuO}, \mathrm{ZnO}$ and $\mathrm{CdO}$ Nanoparticles were taken for further characterizations like XRD, FTIR, UV-Vis and FESEM spectroscopy.

\subsection{Characterization:}

The X-ray diffraction (XRD) patterns of the powdered samples $(\mathrm{CuO}, \mathrm{ZnO}$ and $\mathrm{CdO})$ were recorded using an $\mathrm{X}$ PERT- PRO diffractometer with $\mathrm{CuK \alpha}$ radiation at room temperature. The crystallite size was estimated using the Scherrer equation from the full width at half maximum of the major XRD peak. The morphology and size of the nanoparticles were determined by Field Emission Scanning Electron Microscope (FE-SEM).

\subsection{XRD Analysis}

\section{Results and Discussion}

The XRD patterns of figures confirmed that the crystalline nature of synthesized $\mathrm{CuO}, \mathrm{ZnO}$ and $\mathrm{CdO}$ nanoparticles using same concentration of $\mathrm{CuCl}_{2}, \mathrm{ZnCl}_{2}, \mathrm{CdCl}_{2}, \mathrm{NaOH}$ and PVP by using Co-precipitation method. The crystallographic structures of the samples were examined by X-ray diffraction (XRD).Fig 3.1.1 Shows the XRD pattern of the obtained samples at same concentration of $\mathrm{CuCl}_{2}(0.5 \mathrm{M}), \mathrm{NaOH}(0.25 \mathrm{M})$ and $\operatorname{PVP}(0.1 \mathrm{M})$. All the diffraction peaks at $2 \theta=31.71^{\circ}, 35.48^{\circ}, 38.52^{\circ}, 48.75^{\circ}, 53.36^{\circ}, 57.96^{\circ}, 61.50^{\circ}, 66.32^{\circ}$, $67.93^{\circ}, 72.34^{\circ}$ and $75.38^{\circ}$ with corresponding to the $\mathrm{h} \mathrm{k} l$ values are (llll 110$),\left(\begin{array}{lll}0 & 0 & 2\end{array}\right),\left(\begin{array}{lll}1 & 1 & 1\end{array}\right),\left(\begin{array}{lll}-2 & 0 & 2\end{array}\right),\left(\begin{array}{lll}0 & 2 & 0\end{array}\right)$,

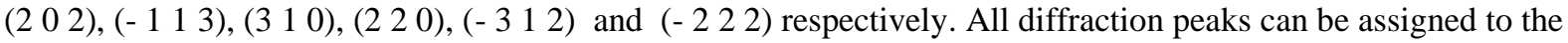
monoclinic structure for $\mathrm{CuO}$. The positions and intensities of peaks are in good agreement with the reported values (JCPDS File No.89-2531) and the earlier literature reported by A.Asha Radhakrishnan et.al[13]. In fig Shows the XRD pattern of the obtained samples at same concentration of $\mathrm{ZnCl}_{2}(0.5 \mathrm{M}), \mathrm{NaOH}(0.25 \mathrm{M})$ and PVP(0.1M). The positions and intensities of peaks are in good agreement with the reported values (JCPDS File No. 891397) and the earlier literature reported by Harish kumar et.al [40]. In Fig Shows the XRD pattern of the obtained samples at same concentration of $\mathrm{CdCl}_{2}(0.5 \mathrm{M}), \mathrm{NaOH}(0.25 \mathrm{M})$ and $\mathrm{PVP}(0.1 \mathrm{M})$. The positions and intensities of peaks are in good agreement with the reported values (JCPDS File No.781125) and the earlier literature reported by Huaming Yang et.al[30] . 


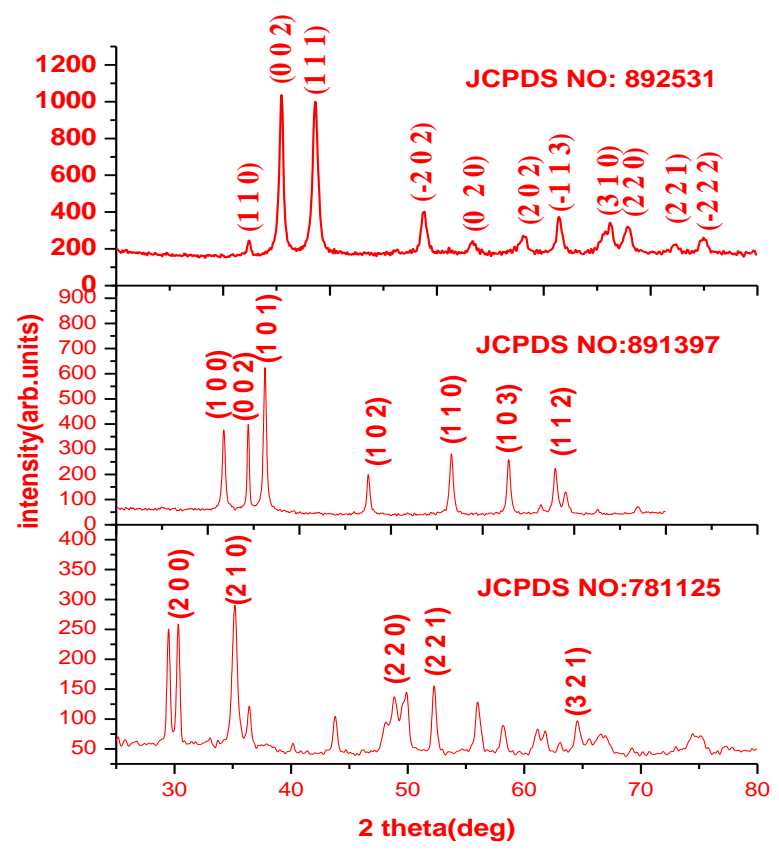

Fig 3.1.1 XRD patterns of $\mathrm{CdO}, \mathrm{ZnO}$ and $\mathrm{CuO}$ nanoparticles

Table 1: Unit Cell parameters and Cell volumes of sample S1, S2 and S3

\begin{tabular}{|l|l|l|l|l|}
\hline \multirow{2}{*}{ Sample code } & \multicolumn{2}{|l|}{ Unit cell parameter $(\mathbf{n m})$} & \multicolumn{2}{l|}{ Cell Volume $(\square)^{\mathbf{3}}$} \\
\cline { 2 - 5 } & Standard & Measured & Standard & Measured \\
\hline \multirow{2}{*}{ S1 } & $\mathrm{a}=4.669, \mathrm{~b}=3.480$ & $\mathrm{a}=4.6963, \mathrm{~b}=3.4435$ & 82.24 & 81.76 \\
\cline { 2 - 3 } & $\mathrm{c}=5.118$ & $\mathrm{c}=5.1189$ & & \\
\hline \multirow{2}{*}{ S2 } & $\mathrm{a}=\mathrm{b}=3.253$ & $\mathrm{a}=\mathrm{b}=3.2518$ & 47.77 & \\
\cline { 2 - 3 } & $\mathrm{c}=5.213$ & $\mathrm{c}=5.2093$ & & \\
\hline S3 & $\mathrm{a}=\mathrm{b}=\mathrm{c}=5.313$ & $\mathrm{a}=\mathrm{b}=\mathrm{c}=5.3308$ & 149.98 & 151.489 \\
\hline
\end{tabular}

The d-spacing values of the peaks were well matched with the reported values in the card. The grain size for different FWHM ( $\beta$ ) values was calculated using Debye-Scherrer's equation.

$$
\mathrm{D}=\mathrm{K} \lambda / \beta \cos \theta
$$

Where, $\mathrm{K}$ is a constant representing shape factor which is about $0.9, \lambda$ is the $\mathrm{X}$-ray wavelength used which is $1.54060 \mathrm{~A}^{\circ}$, while $\beta$ is the full width half maximum (FWHM) of the diffraction angle. The peaks were broad due to the Nano size effect. The average particle or grain size of $\mathrm{CuO}, \mathrm{ZnO}$ and $\mathrm{CdO} N P$ s were found to be $44 \mathrm{~nm}$, $39 \mathrm{~nm}$ and $45 \mathrm{~nm}$. The unit cell parameters and cell volumes of sample S1, S2 and S3 by calculated using UNIT CELL software and it is shown in table (1).

\subsection{FTIR Analysis}

In order to understand the synthesized $\mathrm{CuO}, \mathrm{ZnO}$ and $\mathrm{CdO}$ NPs by Fourier transform infrared spectroscopy technique is used. FTIR analysis was carried out. Fig 3.2.1 represent the FTIR spectrum recorded for the $\mathrm{CuO}, \mathrm{ZnO}$ and $\mathrm{CdO}$ nanoparticles in the range of 4000 to $400 \mathrm{~cm}^{-1}$. The high frequency made at 571,430 and $446 \mathrm{~cm}^{-1}$ in the different concentration of PVP and also in different concentration of $\mathrm{NaOH}$. It may be attributed to the $\mathrm{Cu}-\mathrm{O}$ stretching [13], $\mathrm{Zn}-\mathrm{O}$ stretching [44] and $\mathrm{Cd}-\mathrm{O}$ stretching [47] along the direction. 


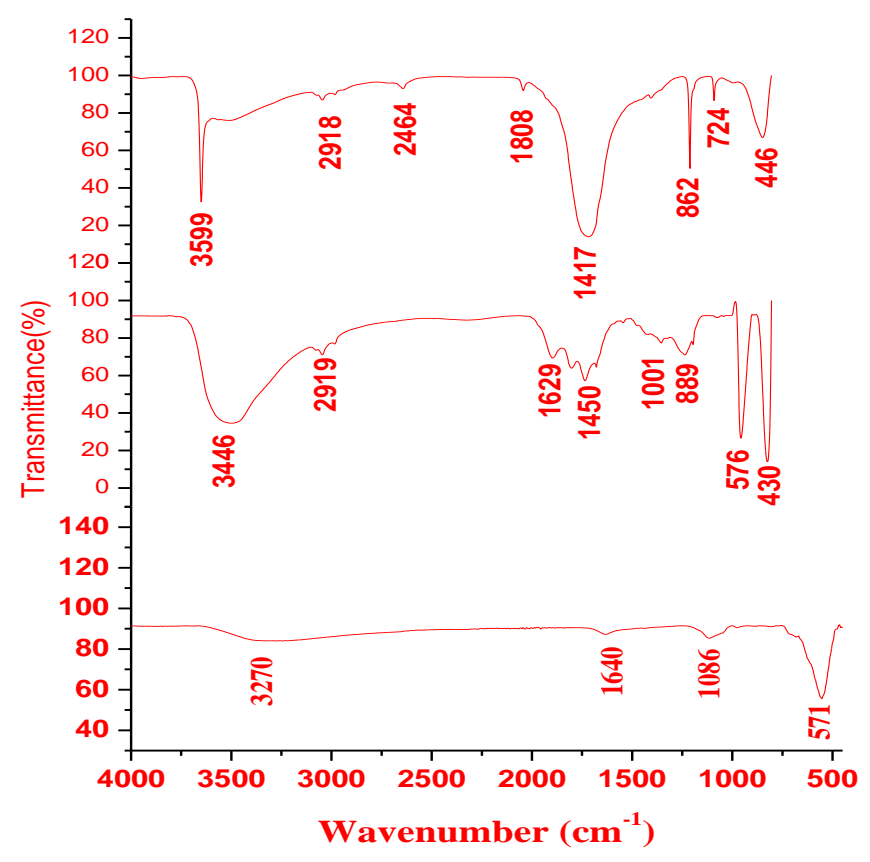

\subsection{UV-VIS Analysis}

Fig 3.2.1 FTIR Pattern $\mathrm{CuO}, \mathrm{ZnO}$ and $\mathrm{CdO}$ Nanoparticles

Fig 3.3.1 illustrates the optical absorption of synthesized $\mathrm{CuO}, \mathrm{ZnO}$ and $\mathrm{CdO}$ NPs. The Spectrum shows the band edge absorption peaks which are found to be at $274 \mathrm{~nm}, 233 \mathrm{~nm}$ and $235 \mathrm{~nm}$.

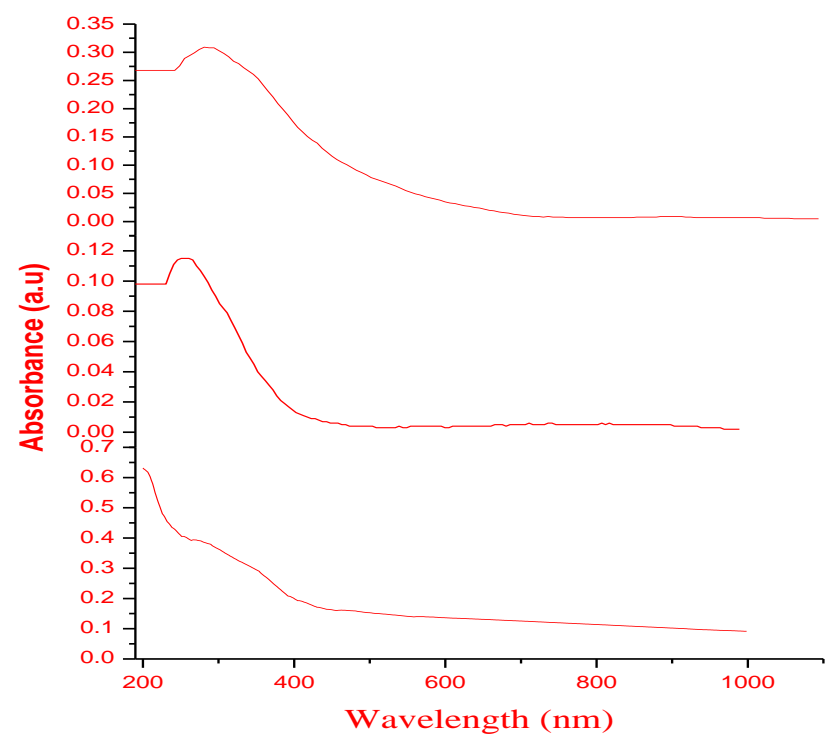

Fig 3.3.1 UV-Visible Absorption spectrum of $\mathrm{CuO}, \mathrm{ZnO}$ and $\mathrm{CdO}$ Nanoparticles

Fig 3.3.2 The Spectrum shows the optical bandgap of $\mathrm{CuO}$ NPs was observed to be $2.3 \mathrm{eV}$ which confirms the $\mathrm{CuO}$ nanoparticles in our sample. The earlier literature reported by C.Yang et.al[38]. optical bandgap of $\mathrm{ZnO}$ was observed to be $2 \mathrm{eV}$ which confirms the $\mathrm{ZnO}$ bond in our sample. the earlier literature reported by $\mathrm{B}$. W. Shivaraj et.al[23] and optical bandgap of $\mathrm{CdO}$ was observed to be $3.9 \mathrm{eV}$ which confirms the $\mathrm{CdO}$ nanoparticle in our sample. The earlier literature reported by A.S. Aldwayyan et.al[47]. 


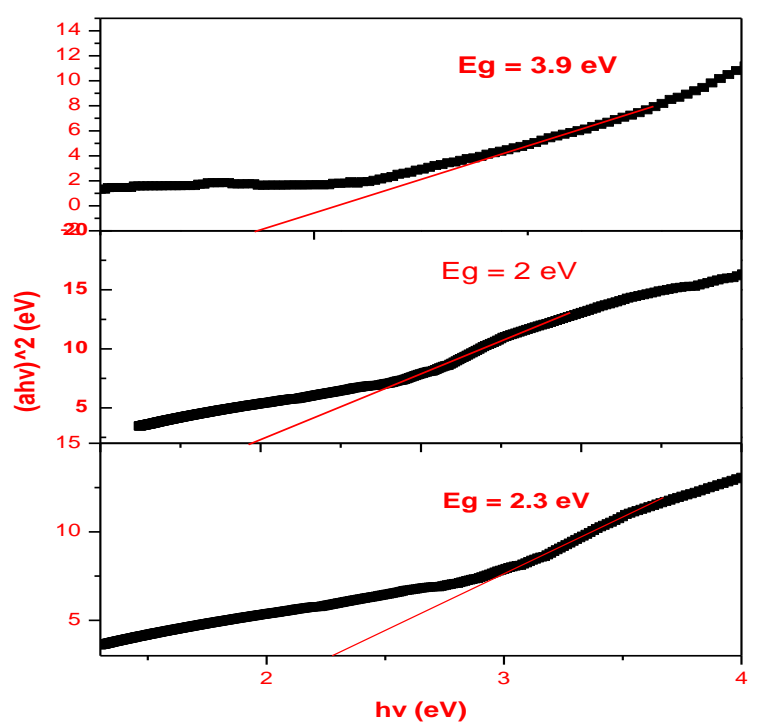

Fig 3.3.2 Optical band gap of $\mathrm{CuO}$ nanoparticles for sample $\mathrm{S} 1$

\section{FESEM Analysis}

FESEM morphological structure of synthesized $\mathrm{CuO}$ nanospheres, $\mathrm{ZnO}$ nanoflakes and $\mathrm{CdO}$ nanosheets for the same concentrations of $\mathrm{CuCl}_{2}, \mathrm{ZnCl}_{2}, \mathrm{CdCl}_{2}$, PVP and $\mathrm{NaOH}$. Fig 3.4.1 shows the FESEM image of the synthesized $\mathrm{CuO}$ nanospheres, from this it confirms the formation of nanospheres. There is some agglomeration formed. The particle sizes of the $\mathrm{CuO}$ nanospheres are $20-30 \mathrm{~nm}$.

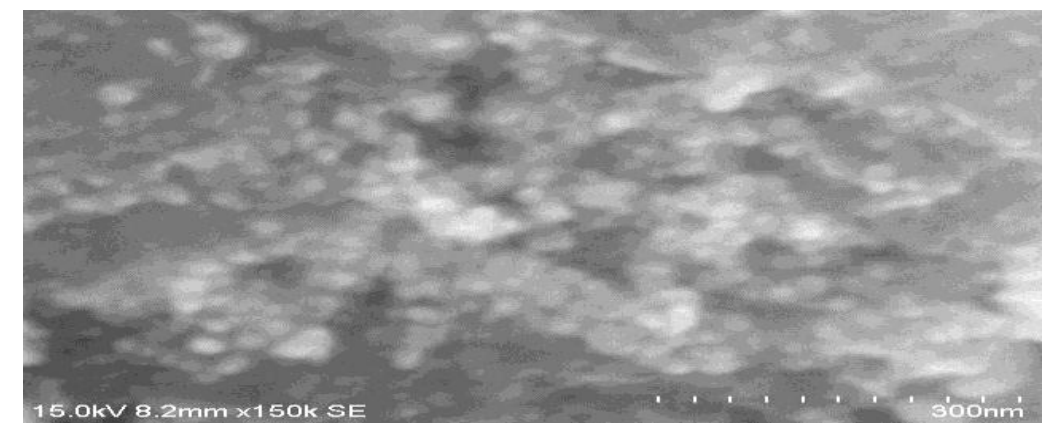

Fig 3.4.1 Shows $\mathrm{CuO}$ nanospheres in $300 \mathrm{~nm}$ magnification

Figures 3.4.2(a) and 3.4.2(b) shows the FESEM image of the synthesized $\mathrm{ZnO}$ nanoflakes, from this it is seemed like to be flakes structure. It confirms the formation of nanoflakes. There is some agglomeration formed. The particle sizes of the $\mathrm{ZnO}$ nanoflakes are $15 \mathrm{~nm}-30 \mathrm{~nm}$ and $15 \mathrm{~nm}-25 \mathrm{~nm}$.

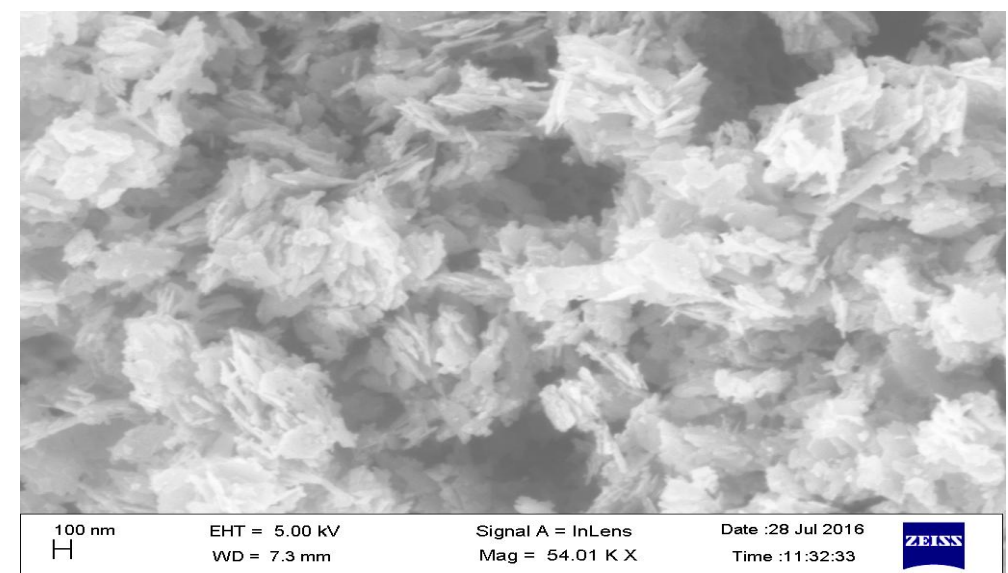

Fig 3.4.2(a) Shows $\mathrm{ZnO}$ nanoflakes in $100 \mathrm{~nm}$ magnification

National Conference on Current Advancements in Physics $3^{\text {rd }} \& 4^{\text {th }}$ February 2017

Department of Physics, St. John's College, Palayamkottai-627 002, Tamilnadu, India. DOI 10.9790/4861-17002014956 


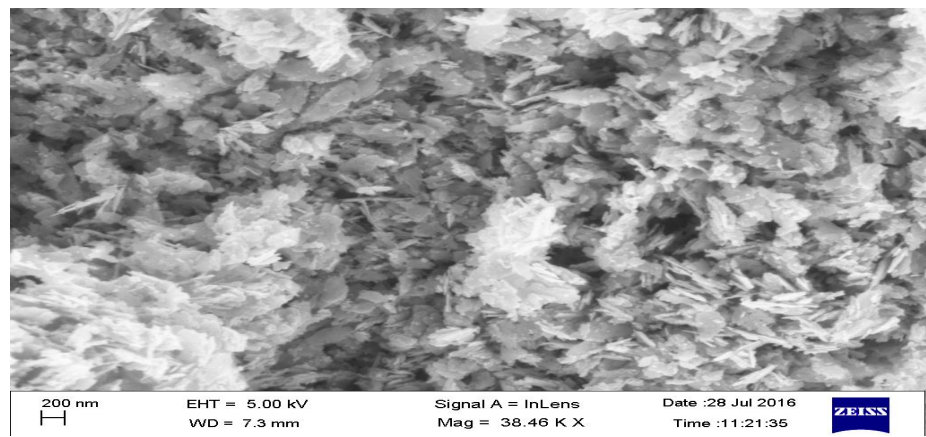

Fig 3.4.2(b) Shows $\mathrm{ZnO}$ nanoflakes in $200 \mathrm{~nm}$ magnification

Figure 3.4.3 shows the FESEM image of the synthesized CdO nanosheets, from this it confirms the formation of nanosheets. There is some agglomeration formed. The particle size of the CdO nanosheets are $(25 \mathrm{~nm} \times 40 \mathrm{~nm})$.

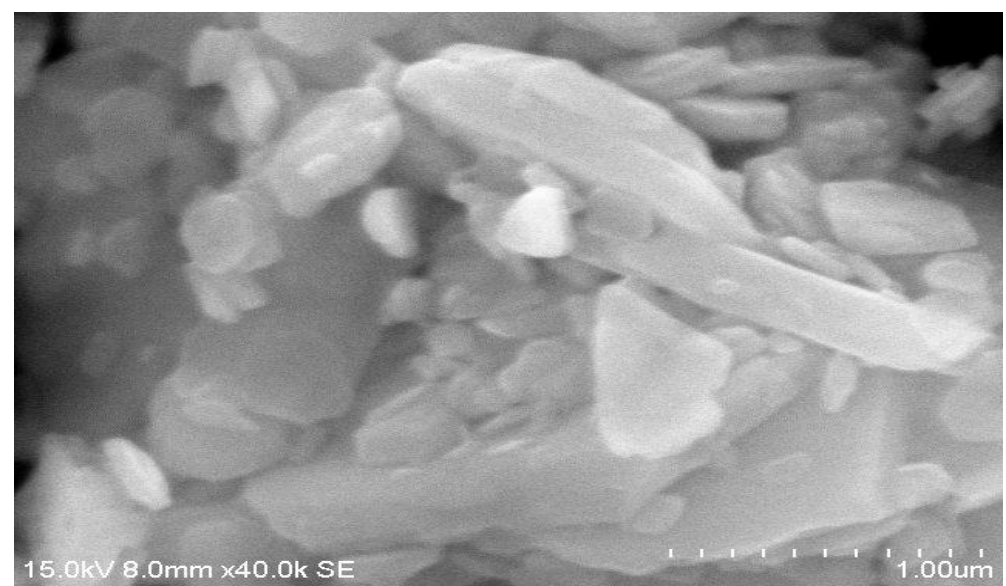

Fig 3.4.3 Shows CdO Nanosheetes in $1 \mu \mathrm{m}$ magnification

\section{Conclusion}

In this work, the $\mathrm{CuO}$ nanospheres, $\mathrm{ZnO}$ nanoflakes and $\mathrm{CdO}$ nanosheets were synthesized by coprecipitation method using PVP as optimizer. The XRD pattern confirms the $\mathrm{CuO}, \mathrm{ZnO}$ and $\mathrm{CdO}$ have the monoclinic, hexagonal and cubic structures respectively. The corresponding grain sizes are $44 \mathrm{~nm}, 39 \mathrm{~nm}$ and $45 \mathrm{~nm}$. The FT-IR study confirmed the functional groups appeared at $571 \mathrm{~cm}^{-1}, 430 \mathrm{~cm}^{-1}$ and $446 \mathrm{~cm}^{-1}$ in $\mathrm{CuO}$, $\mathrm{ZnO}$ and $\mathrm{CdO}$ nanoparticles were due to stretching vibration of $\mathrm{Cu}-\mathrm{O}$, stretching vibration of $\mathrm{Zn}-\mathrm{O}$ and stretching vibration of $\mathrm{Cd}-\mathrm{O}$. The optical studies it shows the absorption peaks of $\mathrm{CuO}, \mathrm{ZnO}$ and $\mathrm{CdO}$ occurs in the range of $274 \mathrm{~nm}, 233 \mathrm{~nm}$ and $235 \mathrm{~nm}$ respectively. The optical band gap energy value for $\mathrm{CuO}, \mathrm{ZnO}$ and $\mathrm{CdO}$ are $2.3 \mathrm{eV}, 2 \mathrm{eV}$ and $3.9 \mathrm{eV}$ and FE-SEM image it confirms the morphology of $\mathrm{CuO}, \mathrm{ZnO}, \mathrm{CdO} . \mathrm{CuO}$ have the formation of nanospheres. $\mathrm{ZnO}$ and $\mathrm{CdO}$ were belongs to formation of nanoflakes and nanosheets structure. The corresponding particle sizes were $20 \mathrm{~nm}-30 \mathrm{~nm}, 15 \mathrm{~nm}-30 \mathrm{~nm}$ and $(25 \mathrm{~nm} \times 40 \mathrm{~nm})$ respectively.

\section{References}

[1]. D. Arun Kumar, Francis P. Xaver and J. Merline Shyla. Investigation on the variation of conductivity and Photoconductivity of $\mathrm{CuO}$ thin films as a function of layers of coating, Archives of Applied Science Research, 2012, $4(5): 2174-2183$.

[2]. K. Nithya, P. Yuvasree, N. Neelakandeswari, N. Rajeskaran, K. Uthayarani, M. Chitra and S. Sathiesh Kumar. Preparation and Characterization of Copper Oxide nanoparticles. International Journal of Chem Tech Research, ISSN : 0974 - 4290, Vol. 6, No.3, pp. 220 - 222, May - June 2014.

[3]. Hui Wang, Jin - Zhong Xu, Jun - Jie Zhu, Hong - Yuan Chen. Preparation of CuO nanoparticles by Microwave irradiation, Journal of Crystal Growth, 244 (2002) $88-94$.

[4]. Chaunyan Ma, Lianjie Zhu, Sifeng Chen, Yan Xing Zhao. Simple and Rapid preparation of CuO Nanowires and Their Optical properties, Material Letters 108 (2013) 114 - 117.

[5]. Narongdet Wongpisutpaisan, Piyanut Charoonsuk, Naratip Vittayakorn and Wisanu Pecharapa. Sonochemical Synthesis and Characterization of $\mathrm{CuO}$ Nanoparticles, $9^{\text {th }}$ Eco - Energy and Materials Science and Engineering symposium, Energy Procedia 9 (2011) $404-409$. 
[6]. A. Asha Radhakrishnan, B. Baskaran Beena. Structural and Optical absorption analysis of CuO nanaparticles, Indian Journal of Advances in Chemical Science, 2(2) (2014) 158 - 161.

[7]. V. Saravanakannan. T. Radhakrishnan. Structural, Electrical and Optical characterization of CuO thinfilms prepared by Spray Pyrolysis Technique, International Journal of Chem Tech Research, ISSN : 0974 - 4290, Vol. 6, No.1, pp. 306 - 310, Jan - March 2014.

[8]. P. Mallick, S. Sahu. Structural, Microstructure and Optical Absorption Analysis of CuO nanoparticles Synthesized by Sol - Gel route, Nanoscience and Nanotechnology 2012, 2(3): $71-74$.

[9]. Amrut. S. Lanje, Satish J. Sharma, Ramachandra B. Pode, Raghumani S. Ningthoujam. Synthesis and Optical characterization of $\mathrm{CuO}$ nanoparticles, Advances in Applied Science Research, 2010, 1(2): 36 - 40. ISSN: 0976 8610.

[10]. Kankanit Phiwdang, Sineenart Suphankij, Wanichaya Mekprasart and Wisanu Pecharapa. Synthesis of CuO nanoparticles by Precipitation Method using Different Precursors, $10^{\text {th }}$ Eco - Energy and Material Science and Engineering, Energy Procedia 34 (2013) 740 - 745.

[11]. Ahmed M. Nawar, Nadia Abdel Aal, Nariman Said, Farid El - Tantawy, F. Yakuphanoglu. Improving the Optical and Electrical Properties of $\mathrm{ZnO}$ thin film by Cupric Oxide dopant. e-ISSN : 2278 - 4861. Volume 6, Issue 4 ver. II (Jul-Aug.2014), pp 17-22.

[12]. Sathyanarayana Talam, Srinivasa Rao Karumuri and Nagarjuna Gunnam. Synthesis, Characterization and Spectroscopic Properties of ZnO nanoparticles. ISRN Nanotechnology, volume 2012, Article ID 372505, 6 pages.

[13]. K. Das, S. Ray, S. chaudhuri and A. B. Marity. Structural and Luminescence Properties of sol-gel derived Cu doped ZnO films. Indian Journal of Pure and Applied Physics. Vol. 47, May 2009, pp. 377 - 382.

[14]. Shriwas S Ashtaputre, Aparna Deshpande, Sonali Marathe, M. E. Wankhede, J. Urban, S. K. Haram, S. W. Gosavi and S. K. Kulkarni. Synthesis and Analysis of $\mathrm{ZnO}$ and CdSe nanoparticles, Premana Journal of Physics, Vol. 65, No. 4, October 2005, pp. $615-620$.

[15]. Mohammad A. Behnajady, Nasser Modirshahla, Elnaz Ghazalian. Synthesis of ZnO nanoparticles by Precipitation Method using Different Precursors, Digest Journal of Nanomaterials and Biostructures, Vol. 6, No. 1, January March 2011, p.467 - 474.

[16]. B. W. Shivaraj, H. N. Narasimha Murthy, M. Krishna and B. S. Satyanarayana. Effect of Annealing Temperature on Structural and Optical Properties of Dips and Spin Coated ZnO thinfilms, Second International Conference on nanomaterials and Technologies, Procedia Materials Science 10 (2015) $292-300$.

[17]. Yangyang Zhang, Manoj K. Ram, Elias K. stefanakos and D. Yogi Goswami. Synthesis, Characterization and Application of ZnO nanowires, Journal of Nanomaterials, Volume 2012, Article ID 624520, 22 pages.

[18]. Ruby Chauhan, Ashavani Kumar and Ram Pal Chaudhary. Synthesis and Characterization of Copper doped ZnO nanoparticles, J. Chem, Pharm, Res., 2010, 2(4): 178 - 183, ISSN NO: 0975 - 7384.

[19]. G. Murugadoss. Synthesis and Characterization of Transition Metals doped ZnO nanorods, J. Mater. Sci Technol., 2012, 28(7), $587-593$.

[20]. P. M. Aneesh, K. A. Vanaja, M. K. Jayaraj. Synthesis of ZnO nanoparticles by Hydrothermal method, Proc. Of SPIE Vol. 6639 66390J - 1, doi : 10. 1117/12.730364.

[21]. I. Warad. Synthesis and Characterization of $\mathrm{CdO}$ nanoparticles Starting from Organometalic Dmphen-CdI 2 Complex.Int.J.Electrochem.sci, 8(2013) 10506 - 10514.

[22]. K. Manickathai, S.Kasi Viswanathan, M.Alagar. Synthesis and Characterization of CdO and CdS nanoparticles. Indian journal of Pure and Applied Physics, Vol.46 August 2008 pp 561-564.

[23]. Huaming Yang, Guanzhou Qiu, Xiangchao zhang, Aidong Tang and Wuguo Yang. Preparation of CdO nanoparticles by Mechanochemical reaction, Journal of Nanoparticles Research $6: 2004,539-542$.

[24]. A.Tadjarodi, M.Imani, H.Kerdari. Apllication of Experimental Design to Optimize the synthesis of CdO cauliflower like nanostructure using Mechanochemical Method, JNS 2 (2012) 127 - 138.

[25]. Azadeh Tadjarodi, Mina Imani and Hamed kerdari. Application of facile solid state process to Synthesize the CdO spherical nanoparticles. International Nano Letters 2013, $3: 43$.

[26]. Maryam Lashanizodeyan. Hoda Mirzazadeh. Synthesis of $\mathrm{Cd}(\mathrm{OH})_{2}$, CdO nanoparticles via a PEG- ASSISTED route. Journal of Ceramic Processing Research, Vol.13, No.4, pp.389 - 391 (2012).

[27]. Asama Natik Naje. Optical Characteristics of CdO nanostructure. Physical Review and Research International. 3(4) : $472-478,2013$.

[28]. B.A.Ezekoye, V.A.Ezekoye, P.O.offor, S.C.Utazi. Synthesis, Structural and Optical Characterizations of Cadmium Oxide thin films by Chemical Path Deposition Technique. International Journal of Physical Sciences, Vol. 8[31], pp.1597-1601, 23 August, 2013.

[29]. Jinsong Liu, Chuanbao Zhao, Ziquanli, Le Yu, Yongcan Li, shanqun Gu, An CaO, Weina Jiang, Jianning Liu and chengtong yang. Solid - State Synthesis, Optical Properties - Controlling studies of CdO nanoparticles, Advanced Material Research

Vols. 228 - 229 (2011) pp.580 - 585

[30]. M. Thambi Durai, N. Murugan, N. Muthukumarasamy, S. Vasantha, R. Bala Sundarapirabu and S. Agilan. Preparation and Characterisation of Nanocrystalline CdS thinfilms. Chalcogenide Letters Vol. 6, No.4, April 2009, pp.172 - 179.

[31]. Ayekpam Bimolini Devi, Dinesh Singh Moirangthem, Narayan Chandra Talukdaar. Novel Synthesis and Characterization of $\mathrm{CuO}$ nanomaterials: Biological Applications, Article in Press : Gmodel CCLET- 3076; No of pages.5.

[32]. chao yang, Feng Xiao, Jide Wang, Xintai Su. Synthesis and Microwave Modification

National Conference on Current Advancements in Physics $3^{\text {rd }} \& 4^{\text {th }}$ February 2017 55 | Page

Department of Physics, St. John's College, Palayamkottai-627 002, Tamilnadu, India. DOI 10.9790/4861-17002014956 
[33]. of $\mathrm{CuO}$ nanoparticles : Crystallinity and Morphological Variations, Catalysis and Gas Sensing, Journal of Colloid and Interface Science 435 (2014) $34-42$.

[34]. Harish Kumar. Structural and Characterization of $\mathrm{ZnO}$ nanoparticles synthesized by Microemulsion Route, 14 (2013) $26-36$.

[35]. Nor Aliya Hamizi, Ch'ng shiau Ying, Mohd Rafie Johan. Different Se Concentrations and Optical studies of CdSe Quantum dots via Inverse Micelle Technique, Int. J. Electrochem. Sci., 7 (2012) 4727 - 4734.

[36]. Steetama Dutta and Bichitra N. Ganguly. Characterization of $\mathrm{ZnO}$ nanoparticles grown in presence of folic acid template, Dutta and Ganguly Journal of Nanotechnology 2012, 10 : 29. Doi: 10 - 1186/ 1477 - 3155 - 10 - 29.

[37]. Mergoramadhayenty Mukhtar, Lusitra Munisa, Rosari Saleh. Co - Precipitation Synthesis and Characterization of Nanocrystalline Zinc Oxide particle Doped with $\mathrm{Cu}^{2+}$ Ions, Material Sciences and Application, 2012, 3, 543 - 551.

[38]. A. Hasanpour, M. Niyaifar, M. Asan. Synthesis and Characterization of $\mathrm{Fe}_{3} \mathrm{O}_{4}$ and $\mathrm{ZnO}$ nanocomposites by Sol - Gel method, Proceeding of the $4^{\text {th }}$ International Conference on Nanostructures (ICNS4), $12-14$ March, 2012.

[39]. Azadeh Tadjarodi, Mina Imani and Hamed Kerdari. Application of a folic solid state process to Synthesize the CdO spherical nanoparticles, International Nanoletters 2013, $3: 43$.

[40]. Hitanshu Kumar, P. B. Barman and Ragini Raj Singh. Development of CdS, ZnS Quantum Dots and Their Core/Shell Structures by Wet Chemical Method, International Journal of Scientific and Engineering Research, Volume 5, Issue 5, May 2014.

[41]. A. S. Aldwayyan, F. M. Al - Noaimi, B. Hammouti, T. B. Hadda, M. Suleiman and I. warad. Synthesis and Characterization of CdO nanoparticles, Int. J. Electrochem. Sci., 8 (2013) 10506 - 10514. 